\title{
Desenvolvimento sustentável, conseqüentes inovações tecnológicas e o futuro da mineração na Amazônia*
}

Roberto C. Villas Bôas - Doutor em Ciências da Engenharia, em Engenharia e Ciências dos Materiais pela COPPE, Universidade Federal do Rio de Janeiro. Atualmente é Pesquisador Titular do Centro de Tecnologia Mineral.

\section{Resumo}

Este texto analisa alguns problemas ambientais causados pela extração e pelo processamento de bens minerais, de interesse para a Amazônia, inclusive a brasileira, e suas conseqüências sociais, tendo em vista o projeto e a produção de produtos e processos ambientalmente e socialmente amigáveis, conhecidos como sustentáveis.

\begin{abstract}
This text analyses some environment problems caused by extraction and ore processing interested for the Amazonia including the Brazilian one and its social consequences as well as the project and the producing of products besides environmental and friendly socially processes been known as sustained.
\end{abstract}

\section{Keywords}

Sustainable development, mining and Amazon.

Desenvolvimento sustentável, mineração e Amazônia.

i apresentado como Conferência Plenária no

Na sua versão original, o texto em inglês foi
Churchill College, sob a égide da Hydromet. 


\section{INTRODUÇÃO}

A produção e a utilização de materiais em geral, e, em conseqüência, de minérios e metais, obedecem, dentro de um determinado quadro de desenvolvimento industrial, aos ciclos econômicos atuantes num igualmente determinado referencial de tempo. Tais ciclos já foram exaustivamente descritos na literatura (MALENBAUM, 1978; TILTON, 1986; VILLAS BÔAS, 1987; WADDELL; LABYS, 1988) e podem refletir tendências mundiais, locais ou mesmo geopolíticas.

Como a seleção de um determinado grupo de materiais depende, fortemente, do ciclo predominante nos países industrializados, estes determinarão, em maiores ou menores graus, os padrões de consumo de commodity, induzindo o mercado a adaptar-se a essa nova realidade.

Nas indústrias intensivas em materiais, duas estratégias são adotadas: buscam-se materiais que se adaptem a uma dada tecnologia (caso da indução descrita no parágrafo anterior) ou, alternativamente, desenvolve-se uma tecnologia para o material disponível (se for difícil comprar o material em causa ou se a situação geopolítica estiver conflituosa).

Os materiais reciclados, cuja magnitude de uso nas indústrias varia de acordo com o estágio econômico de uma particular economia, necessitam, como regra geral, de menos capital e gasto energético e de mais mão-de-obra do que os empregados na extração primária, a partir do minério. Também, em geral, exigem menores custos de controle da poluição! Entretanto, a reciclagem torna-se mais intensa com o aumento da sofisticação da economia, pois que, então, quantidades apreciáveis de material a ser reciclado ficam disponíveis!

Os materiais, durante seus processos produtivos, produzem importantes alterações no meio ambiente, pois requerem energia para serem processados, terras nas quais se instalem suas fábricas, áreas de recebimento de dejetos resultantes dos processos produtivos, além de expelirem gases e poeiras e exigirem água e constante movimentação de terra e solo!

Na verdade, já de há muito esses fatos são conhecidos, e algumas ações foram tomadas, aqui e ali, no sentido de minimizar seus efeitos, deixando-os dentro de "limites aceitáveis de tolerância", que variam de tempos em tempos.

Tal variabilidade deve-se às pressões sociais, que forçam legislações, que, por sua vez, promovem mudanças tecnológicas no processo, as quais, por fim, refletem-se na economia!

Naquilo que diz respeito à temática ambiental e à extração mineral, duas questões surgem. A primeira é: qual é o efeito da produção, do rejeito e do uso dos materiais? A segunda é: quais são suas disponibilidades num futuro previsível? 
Este texto abordará a primeira questão, analisando e comentando algumas commodities de interesse amazônico, bem como fazendo algumas ilações sobre as conseqüências sociocomunitárias, como as questões do fechamento de minas e dos indicadores de sustentabilidade para a indústria extrativa mineral.

\section{A RECUPERAÇÃO MÉdiA DOS METAIS E SUAS ETAPAS DE PRODUÇÃO}

Qualquer material, para ser produzido, deve passar por etapas de produção, nas quais também são gerados rejeitos. Esses rejeitos podem ser genericamente classificados em duas grandes categorias: perdas e efluentes.

Perdas são aqueles rejeitos facilmente identificáveis a partir do material produzido, ou seja, partes do material que vão ficando para trás ao longo do processo produtivo.

Efluentes são rejeições originadas nas mesmas etapas de produção, decorrentes da tecnologia utilizada em cada etapa, mas não necessariamente relacionadas ao material principal.

\subsection{A recuperação média dos metais}

Numa tentativa de sistematizar a análise dos impactos ambientais dos rejeitos oriundos da indústria minerometalúrgica, tomem-se, por exemplo, os metais e conceituem-se, quantificando-as, as denominadas perdas médias metálicas.

É bem conhecido o fato de que as recuperações associadas aos minérios, desde a mina até o produto final, variam de economia para economia, de país para país, em função das tecnologias empregadas, das leis vigentes ou dos acatamentos voluntários de regulamentações ambientais e sociais, hoje em dia muito em voga, da capacidade financeira das empresas, da habilidade no trato industrial e ambiental, de pressões sociais e políticas, etc. O mesmo se aplica aos impactos ambientais causados pela produção primária e secundária, por meio da reciclagem, dos metais.

Assim, dados sobre recuperações e perdas médias podem apresentar variações apreciáveis, de metal para metal e mesmo de país para país para um mesmo metal, ainda que se utilizem tecnologias similares. Isso se deve às denominadas "particularidades" do mundo mineral: a combinação ótima entre o teor de corte da jazida, ou seja, o limite lavrável, e o compromisso entre recuperação e teor do concentrado, o que torna cada jazida única nas suas características físicas e econômicas.

Se outras variáveis são mantidas iguais, quanto menor o teor ou pobre a qualidade do minério, tanto maior será o custo de recuperação 
do produto de interesse. Quando há uma escolha do teor do minério a ser minerado, há também uma escolha da massa total a ser extraída, bem como do total recuperado do produto. Quanto menor o teor permitido, maior será a massa extraída.

Dessa forma, a fixação do teor de corte em jazidas com graus irregulares de distribuição de teores poderá requerer várias seqüências de computações alternativas entre teores e massas, obviamente em função das hipóteses sobre os limites de lavra.

Igualmente importante é a trabalhabilidade do minério, medida pelo custo da remoção física da rocha. Outros fatores, como o acesso à mina, a espessura e a regularidade da zona mineralizada, a dureza, a presença de estruturas interferentes etc., são parâmetros para cálculos e decisões a tomar.

Variações quanto ao teor e à trabalhabilidade de um corpo mineral podem acompanhar-se mutuamente e, mesmo, compensar-se umas às outras. Minérios de diferentes teores e custos, mas suficientemente similares em outras características para tornarem-se insumos do mesmo processo de beneficiamento, poderão ser extraídos ou homogeneizados visando uma recuperação proveitosa ou, caso contrário, permanecerão como minérios paramarginais.

Uma remoção completa de todo o minério disponível na mina, ou lavra total, nunca é conseguida, mesmo porque não almejada, visto que o custo de extração por unidade recuperada cresce continuamente e, em geral, aceleradamente, quando tentativas são feitas para incrementar o percentual extraído.

A curto prazo, para uma dada usina de beneficiamento, o percentual lavrável dependerá, em boa proporção, do teor do minério; o método de lavra normalmente limita a recuperação do minério na boca da mina (CORRY; KIESSLING, 1938; VILLAS BÔAS, 1976).

Como exemplo interessante da tecnologia de processo, citamos as recuperações para a lixiviação de ouro, mostradas na Tabela 1.

Tabela 1: Recuperações de ouro por processos de lixiviação.

\begin{tabular}{l|c|c|c|c}
\hline \multicolumn{1}{c|}{ Operação } & Partícula & Recuperação & Tempo & Custo \\
\hline Agitação & $\leq 0,1 \mathrm{~mm}$ & $90 \mathrm{a} 95 \%$ & $>20 \mathrm{~h}^{*}$ & $\mathrm{IN}+\mathrm{OP} *$ \\
Vat & $\leq 10 \mathrm{~mm}$ & $70 \mathrm{a} 80 \%$ & $3 \mathrm{a} 4 \mathrm{~h}^{*}$ & $\mathrm{IN}^{*}$ \\
Pilha & $>10 \mathrm{~mm}$ & $40 \mathrm{a} 60 \%$ & $3 \mathrm{a} 4 \mathrm{~s}^{*}$ & $\mathrm{IN}+\mathrm{OP} *$ \\
\hline
\end{tabular}

${ }^{*} \mathrm{IN}=$ custos de investimento; OP = custos operacionais; $\mathrm{h}=$ hora; $\mathrm{s}=$ semana. Fonte: BAHR; PRIESEMANN, 1988.

Vejam-se, agora, algumas commodities minerais selecionadas e suas recuperações e teores. Na Tabela 2, MC equivale à massa do concentrado produzido em relação à do minério total, em percentagem, 
e MR é a recuperação em massa, ou seja, aquilo que é recuperado da commodity em questão, relativa à quantidade de minério na boca da mina (run of mine). Esses índices percentuais, por si sós, comprovam a dimensão do problema ambiental enfrentado.

Tabela 2: Recuperação x teor para algumas commodities.

\begin{tabular}{|c|c|c|c|}
\hline Minério & Recuperação & Teor & Empresa \\
\hline $\begin{array}{l}\mathrm{Nb}_{2} \mathrm{O}_{5}(3 \%) \\
\text { Pirocloro }\end{array}$ & $\begin{array}{l}M C=3,3 \% \\
M R=66 \%\end{array}$ & $\begin{array}{l}60 \% \mathrm{Nb}_{2} \mathrm{O}_{5} \\
\text { concentrado }\end{array}$ & $\begin{array}{l}\text { CBMM } \\
\text { (9) }\end{array}$ \\
\hline $\begin{array}{l}\mathrm{TiO}_{2}(1,5 \%) \\
\text { IImenita } \\
\mathrm{Cr}_{2} \mathrm{O}_{3}(17 \%) \\
\text { Cromita }\end{array}$ & $\begin{array}{l}M C=2,2 \% \\
M R=81 \% \\
M C=28 \% \quad 37 \\
M R=65 \%\end{array}$ & $\begin{array}{l}55 \% \mathrm{TiO}_{2} \\
\text { concentrado } \\
46 \% \mathrm{Cr}_{2} \mathrm{O}_{3} \\
\text { concentrado }\end{array}$ & $\begin{array}{l}\text { RIB } \\
(9) \\
\text { FERBASA } \\
(9)\end{array}$ \\
\hline $\begin{array}{l}\mathrm{WO}_{3}(0,5 \%) \\
\text { Scheelita } \\
\mathrm{SnO}_{2}(1,3 \%) \\
\text { Cassiterita }\end{array}$ & $\begin{array}{l}M C=0,49 \% \\
M R=79 \% \\
M C=1,9 \% \\
M R=69,1 \%\end{array}$ & $\begin{array}{l}75 \% \mathrm{WO}_{3} \\
\text { concentrado } \\
48 \% \mathrm{Sn} \\
\text { concentrado }\end{array}$ & $\begin{array}{l}\text { TUNGST } \\
(9) \\
\text { RENISON } \\
(10)\end{array}$ \\
\hline $\begin{array}{l}\mathrm{Ta}_{2} \mathrm{O}_{5}(0,16 \%) \\
\text { Tantalita }\end{array}$ & $\begin{array}{l}M C=0,22 \\
M R=70 \%\end{array}$ & $\begin{array}{l}49 \% \mathrm{Ta}_{2} \mathrm{O}_{5} \\
\text { concentrado }\end{array}$ & $\begin{array}{l}\text { BERNIC } \\
\text { (10) }\end{array}$ \\
\hline
\end{tabular}

Outro exemplo bastante ilustrativo da sinergia entre recuperação, teor, massa recuperada, movimento de terra para acesso ao corpo mineral, subprodutos gerados, etc. é a produção de fertilizante fosfatado, a partir de rocha vulcânica, o qual, além dos problemas de manuseio de terra e solo e de disposição de rejeitos, gera, no seu processamento, cinco vezes mais massa, em gesso, do que o concentrado de P2O5 produzido, ao reagir com ácido sulfúrico.

\subsection{As etapas de produção}

Num processo produtivo, podem-se identificar quatro etapas: a extração, o processamento, a fabricação e a manufatura.

A etapa de extração diz respeito à lavra e ao beneficiamento do minério. O produto que daí resulta é o concentrado comercial. Nessa etapa, as perdas dependem do método de mineração empregado - a céu aberto, câmara e pilares, corte e enchimento, etc. - e das técnicas de beneficiamento - gravíticas, flotação e outras. Os efluentes gerados são COx e NOx, a partir das máquinas e dos equipamentos, das águas de processo, do lençol freático contaminado, do material particulado e da movimentação de solo e terra.

A etapa de processamento envolve as operações metalúrgicas e/ou químicas para converter o concentrado em metal ou composto. As perdas dependem da tecnologia seguida e das habilidades e tecnologias disponíveis (piro, hidro e/ou eletro). Os efluentes são gases - COx, NOx e SOx -, bem como líquidos, na forma de metais pesados contidos nas águas de processamento, e sólidos, como sedimentos e poeiras de metais pesados. 
A etapa de fabricação caracteriza-se pelas operações destinadas ao fabrico de barras, chapas, etc.. As perdas nesse caso são recirculadas ad infinitum, sem perdas do material (BEEVER, 1982). Os efluentes são as águas servidas e os gases industriais.

Na etapa de manufatura, são realizadas operações mecânicas para a conformação dos metais, como estamparia e forja. As perdas são as partes do metal resultantes de tais conformações que não produzem o produto desejado (BEEVER, 1976; BEEVER, 1982; CHAPMAN; ROBERTS, 1983; MAR, 1981). A reciclagem é bem organizada e eficiente, mas não total (BEEVER, 1976; CHAPMAN; ROBERTS, 1983). Os efluentes são vapores de água e gases industriais.

Os dados sobre a recuperação média dos metais referentes às etapas de extração e processamento foram obtidos a partir de Hasialis (1975) e os referentes à etapa de manufatura, a partir de Mar (1981). Ressalte-se que os dados dessa última referência são bastante antigos para os Estados Unidos, tendo sofrido alterações substanciais ao longo destes anos; entretanto, para aquelas partes do mundo que não estão utilizando as best available technologies (BAT), ainda podem ser representativos. De qualquer maneira, o importante aqui é o argumento, qualquer que seja o número que o represente, o qual deverá ser pesquisado e levantado para cada caso específico.

Quanto aos dados fornecidos por Hasialis, representam valores médios, e, como é natural, grandes variações existem para cada caso particular de interesse. Entretanto, mais uma vez, vale o argumento, deixando-se ao leitor a tarefa de descobrir os dados representativos para o seu próprio caso de interesse.

As etapas de produção estão representadas na Figura 1, que é um diagrama de Sankey, ou de tiras, envolvendo as quatro etapas descritas.

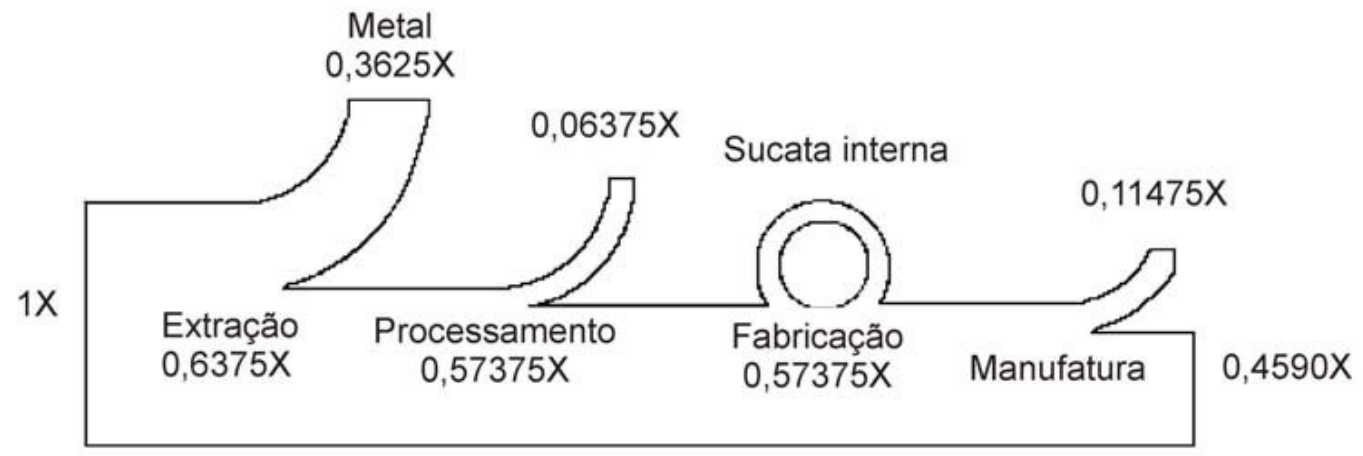

Figura 1: Diagrama de Sankey das etapas de produção.

$\mathrm{X}=$ teor do metal no minério in situ: $1 \mathrm{X}$.

Le $=$ perdas do metal resultantes da etapa de extração: 0,3625 X.

$\mathrm{Pe}=$ produto, em metal, resultante da etapa de extração: 0,6375 X.

$\mathrm{Lp}=$ perdas do metal resultantes da etapa de processamento: 0,06375 X.

$\mathrm{Pp}=$ produto, em metal, resultante da etapa de processamento: 0,57375 X. 
Lf $=$ perdas do metal resultantes da etapa de fabricação: 0 X.

Pf $=$ produto, em metal, resultante da etapa de fabricação: Pp.

$\mathrm{Lm}=$ perdas do metal resultantes da etapa de manufatura: 0,11475 X.

$\mathrm{Pm}=$ produto, em metal contido, resultante da etapa de manufatura: 0,459X. $\mathrm{Ei}$ = efluente gerado em cada uma das etapas de produção, mostrado nas figuras a seguir.

\subsubsection{Identificação dos impactos ambientais da etapa de extração} Observe-se a Figura 2.

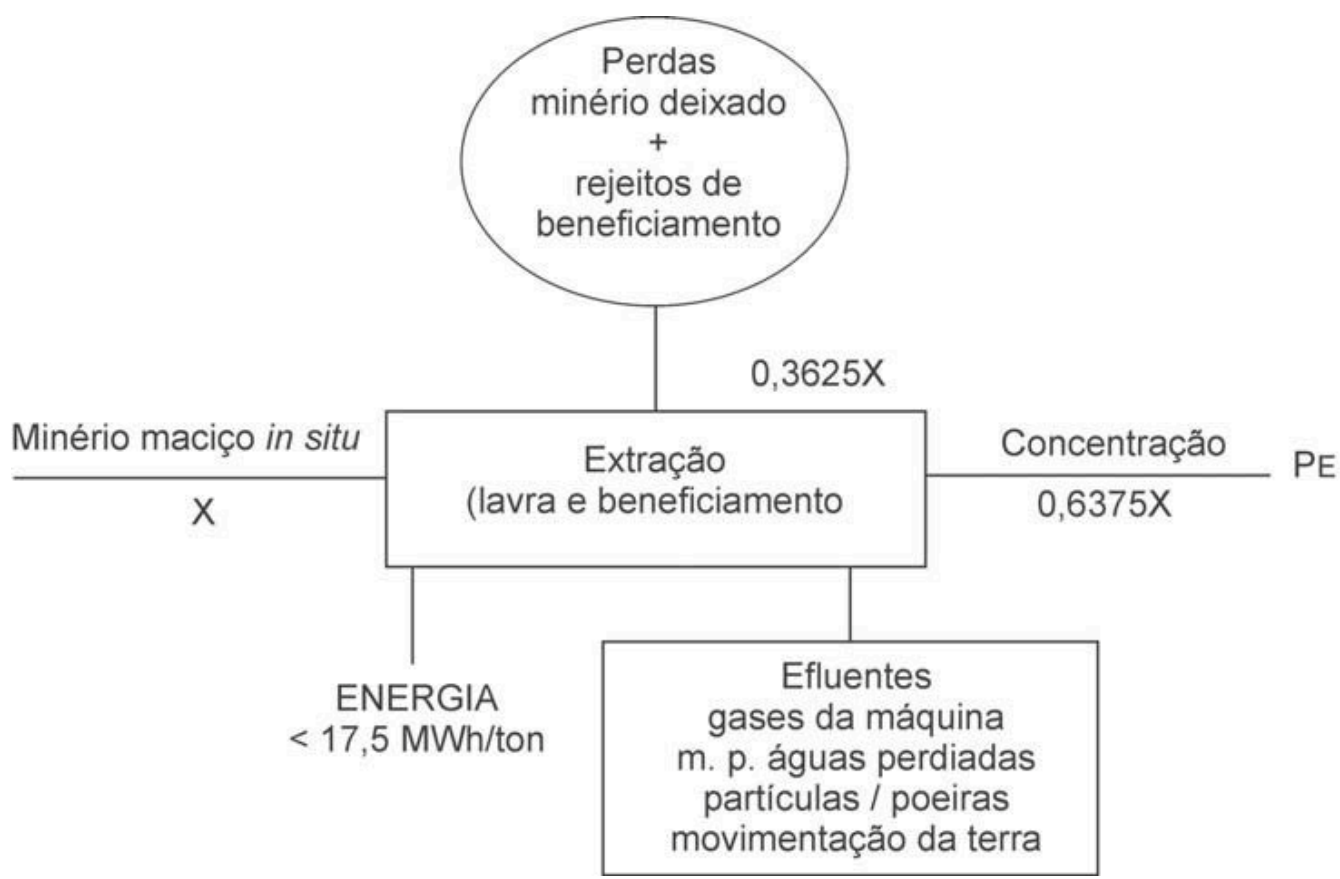

Figura 2: Entradas e saídas da etapa de extração.

\section{A - Energia:}

Há possibilidades de melhoras técnicas quanto à energia utilizada nessa etapa. Os dados estão em kWh (térmico), por tonelada de metal primário (YOSHIKI-GRAVELSINS et al., 1993, p. 15-20):

$\mathrm{Al}=10.175 \mathrm{kWh}$ (térmico)/tonelada;

$\mathrm{Cu}=17.420 \mathrm{kWh}$ (térmico)/tonelada;

$\mathrm{Zn}=1.420 \mathrm{kWh}$ (térmico)/tonelada.

\section{B - Perdas:}

Minério deixado in situ, resultante do método de lavra e do teor de corte selecionado. Há possibilidade de melhoras.

Rejeitos do beneficiamento, decorrentes da tecnologia empregada na etapa de processamento, pois os teores comerciais são insumos para tecnologias conhecidas. Há possibilidades de melhoras. 


\section{C - Efluentes:}

$\mathrm{Na}$ lavra, impactos originados das operações de acesso e de movimentação de rochas e terra em geral. Há possibilidades de melhoras se forem estabelecidas medidas legais ou voluntárias que levem em conta os custos de recuperação e as pressões sociais.

Na lavra, gases das máquinas e equipamentos, barulhos e vibrações. Há possibilidades de melhoras.

Ainda na lavra, ruptura do lençol freático e outros regimes hidráulicos existentes. Há poucas possibilidades de melhoras com os métodos de mineração empregados hoje em dia.

No beneficiamento de minérios, as águas de processo e poeiras, bem como a disposição de rejeitos e o controle de geração de ácidos e outros efluentes.

\subsubsection{Identificação dos impactos ambientais da etapa de processamento}

Observe-se a figura 3.

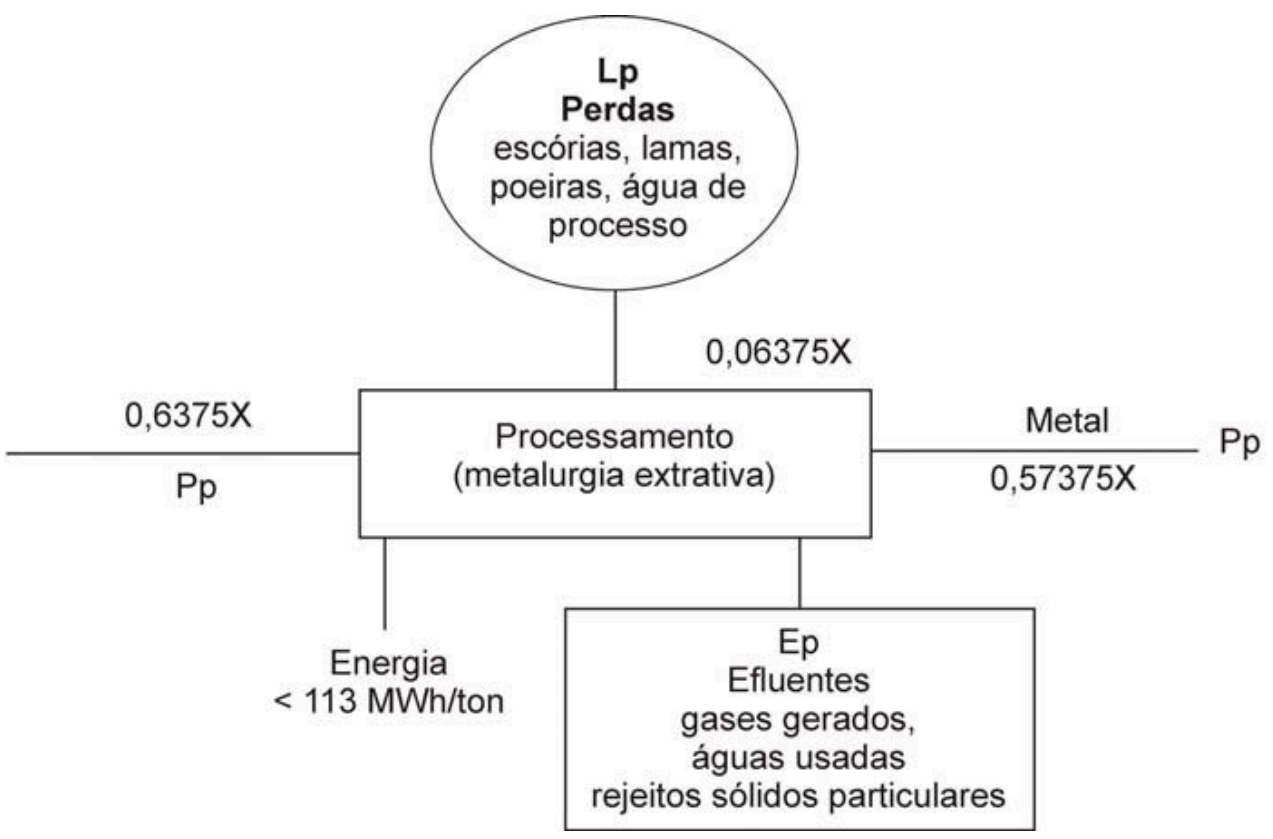

Figura 3: Entradas e saídas da etapa de processamento.

\section{A - Energia:}

No uso de energia, há possibilidades de melhora de desempenho. Os dados são em kWh(térmico)/tonelada (YOSHIKI-GRAVELSINS et al., 1993):
Al: $35.384 \mathrm{kWh}$ (térmico)/tonelada;
Cu: 26.520 kWh (térmico)/tonelada;
Zn: $17.560 \mathrm{kWh}$ (térmico)/tonelada;
Mg: $103.000 \mathrm{kWh}$ (térmico)/tonelada. 
B - Perdas:

As massas perdidas nesta etapa dependem da tecnologia de processo utilizada, das habilidades disponíveis e da legislação. Há possibilidades de melhoras, especialmente nas áreas de recuperação de metais de escórias, poeiras e outras massas descartadas, ou de desenvolvimento de novos processos tecnológicos baseados nos decréscimos das operações envolvidas e/ou em equipamentos mais eficientes.

\section{C - Efluentes:}

Gases de processamento, como COx, NOx, SOx, além das águas de serventia após a eventual remoção de metais pesados dessas águas de processamento. Emissão de particulados, ao longo do processo, além de rejeitos sólidos, outros que escórias, lamas, etc. Há possibilidades de melhoras.

1.2.3 Identificação dos impactos ambientais da etapa de fabricação Observe-se a Figura 4.

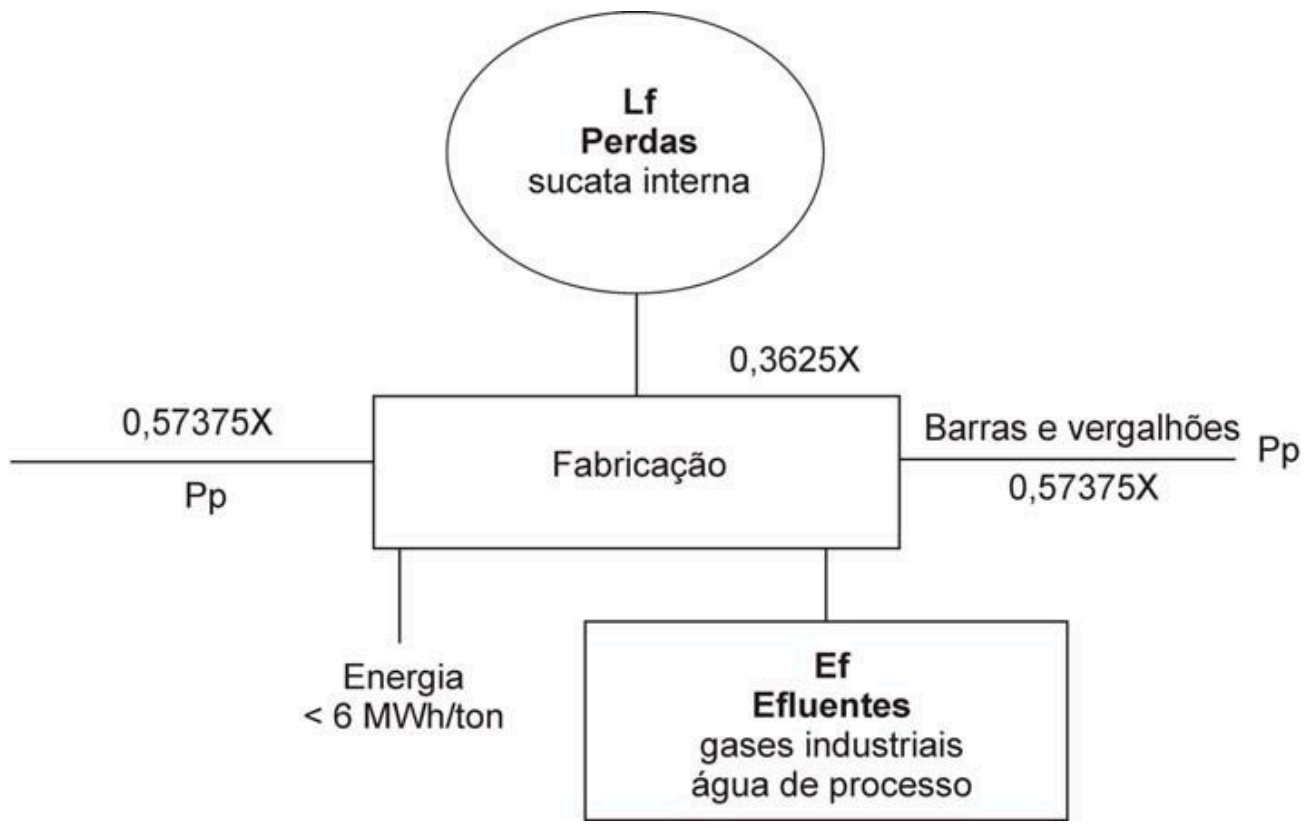

Figura 4: Entradas e saídas da etapa de fabricação.

\section{A - Energia:}

Utilização de energia, tal como mostrado pelos números a seguir, obtidos de Yoshiki-Gravelsins et al. (1993):

$\mathrm{Al}: 4.937 \mathrm{kWh}$ (térmico)/tonelada;

$\mathrm{Cu}: 5.970 \mathrm{kWh}$ (térmico)/tonelada;

Zn: 1.492 kWh (térmico)/tonelada. 


\section{B - Perdas:}

Geração da denominada home scrap, em que não há perdas, pois a reciclagem é contínua e constante. Entretanto, há possibilidades de melhoras, ou seja, decréscimos, das massas geradas como perdas, com a utilização de operações e/ou equipamentos mais eficazes.

1.2.4 Identificação dos impactos ambientais da etapa de manufatura Observe-se a Figura 5.

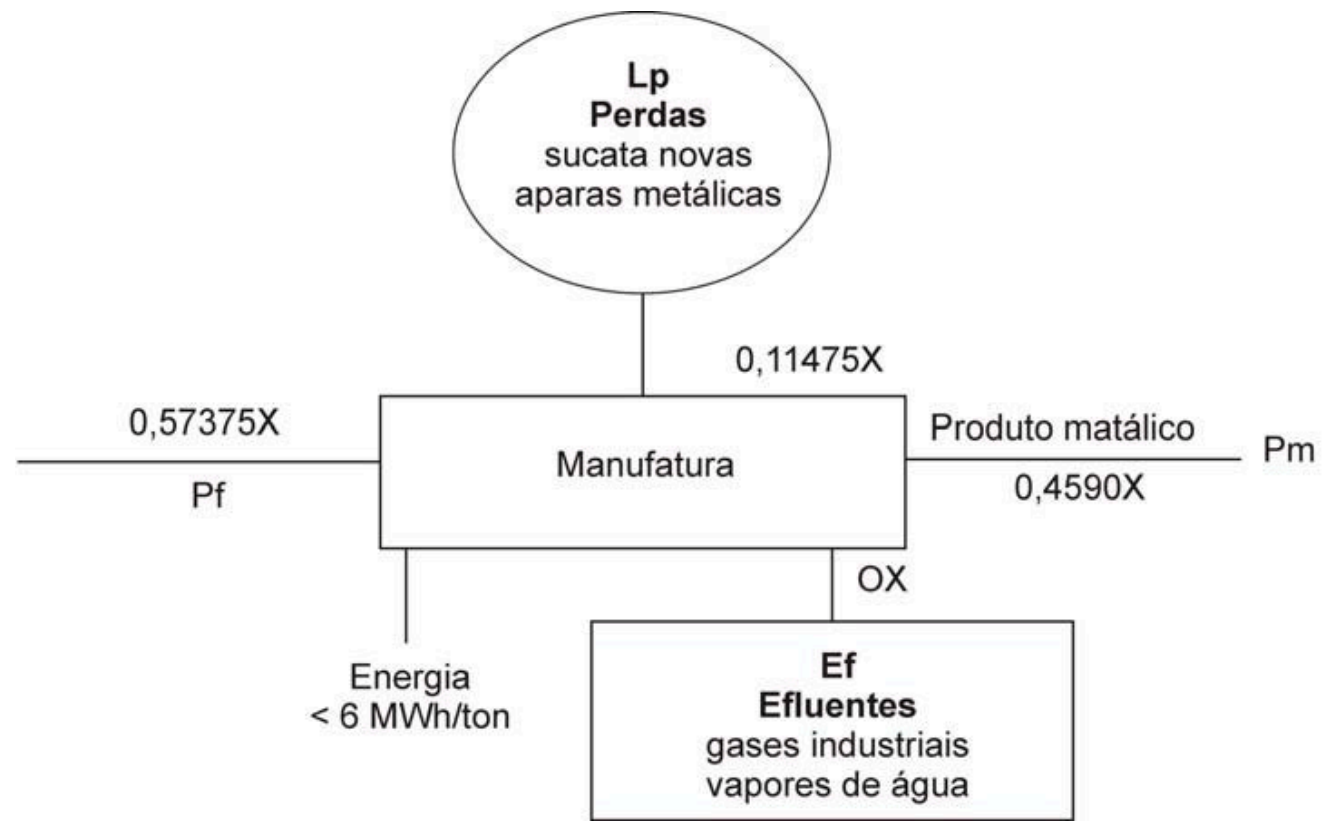

Figura 5: Entradas e saídas da etapa de manufatura.

\section{A - Energia:}

Bastante variável, dependendo do particular produto metálico obtido por meio de forja, estamparia, usinagem, etc. Entretanto, bem menos variável do que qualquer uma das etapas de produção anteriores.

\section{B - Perdas:}

São as denominadas "sucatas novas", as quais são recicladas na produção secundária do metal em questão.

\section{C - Efluentes:}

Gases industriais e vapor d'água.

\section{O PAPEL DO ENGENHEIRO MINERAL}

Conard (1992) faz uma apresentação geral do papel do profissional de operação e pesquisa imbuído do escopo do desenvolvimento 
sustentável no seu dia-a-dia operacional. A drenagem ácida, a remoção dos metais dos efluentes industriais, o gerenciamento do arsênico, a redução de poluentes gasosos e a conservação da energia, a destruição de cianetos, o processamento dos rejeitos e a reciclagem são matérias analisadas e discutidas pelo autor, que dá exemplos selecionados de técnicas hidrometalúrgicas para garantir um meio ambiente saudável.

Para os interessados em novas técnicas e assuntos de pesquisa em hidrometalurgia e processamento aquoso de materiais e minerais industriais, as revisões de Doyle e Duyvesteyn (1993) são indicadas, bem como as periodicamente publicadas por Nicol (1993), como revisões de extração e processamento.

Tabela 3: Etapas de produção do minério.

\begin{tabular}{l|c}
\hline \multicolumn{1}{c|}{ Etapas de produção } & Energia $\left(\right.$ MWh(térmico)/ $/$ t $\left.^{*}\right)$ \\
\hline Extração & $<17,5$ \\
Processamento & $<113,0$ \\
Fabricação & $<6,0$ \\
Manufatura & $<<6,0$ \\
\hline
\end{tabular}

Os dados mencionados não são médias, mas valores máximos para uma classe selecionada de metais (Al, Cu, Zn, Mg e Ti).

Assim, o papel do engenheiro mineral, químico ou hidrometalurgista e mesmo do planejador ambiental é buscar processos que minimizem a energia consumida. Dessa forma, a atenção deverá estar majoritariamente voltada para a etapa de processo, seguida da de extração e, secundariamente, das etapas de fabricação e de manufatura.

As eficiências das operações de processamento foram computadas por Chapman e Roberts (1983), bem como em outras referências sobre o assunto, como Yoshiki-Gravelsins et al. (1993) e Forrest e Szekely (1991).

Tabela 4: Eficiências energéticas de alguns metais selecionados para a etapa de processamento.

\begin{tabular}{c|c}
\hline Metais primários & Eficiências energéticas(\%) \\
\hline $\mathrm{Al}$ & 13 \\
$\mathrm{Cu}$ & 1,4 \\
$\mathrm{Zn}$ & 5,5 \\
$\mathrm{Mg}$ & 6,1 \\
$\mathrm{Ti}$ & 4,1 \\
\hline
\end{tabular}

Para os objetivos desta análise, interessam as eficiências energéticas totais na etapa de processamento, ou seja, a energia usada por todas as etapas, e não apenas aquela diretamente vinculada ao processo propriamente dito, comparada à energia termodinâmica, a 
energia livre de Gibbs, para aquela mesma etapa de processamento, pois representam fortíssimas indicações onde buscar melhoras energéticas de processamento. A Tabela 4 lista tais eficiências para metais selecionados (CHAPMAN; ROBERTS, 1983; YOSHIKIGRAVELSINS et al., 1993).

É evidente o interesse da fonte de energia, baseada em hidrelétrica ou em carvão, dado o efeito estufa. Forrest e Szekely (1991) analisaram em detalhe esse fato.

\subsection{Perdas}

A Tabela 5 apresenta as perdas médias de metal no meio ambiente, para cada etapa de produção.

Tabela 5: Perdas médias de metal por etapa de produção.

\begin{tabular}{lcc}
\hline \multicolumn{1}{c|}{ Etapa } & Perdas médias \\
\hline Extração & $0,3625 \mathrm{X}$ \\
Processamento & $0,06375 \mathrm{X}$ \\
Fabricação & 0 \\
Manufatura & $0,11475 \mathrm{X}$ \\
\hline
\end{tabular}

O engenheiro de processo ou o planejador ambiental deverá focar sua atenção na etapa de extração, onde se concentram as maiores perdas, e depois nas etapas de manufatura e de processamento.

É importante salientar, mais uma vez, que os números apresentados, como são médias de classes de substâncias, apresentam grandes variações. Então competirá ao engenheiro de processo ou ao planejador ambiental obter os números de interesse e referentes ao seu particular metal e/ou substância, visto que nossa argumentação é perfeitamente aplicável e válida como ferramenta de estudo.

Não obstante, pode-se afirmar que, em geral, a mineração e o beneficiamento são os grandes responsáveis pelas maiores perdas, em massa. Assim, por exemplo, quando aplicáveis, as técnicas de lavra química, in situ, devem ser preferidas (obviamente, levando-se em conta as variáveis permeabilidade, trabalhabilidade, solubilidade, etc.) quando o objetivo é a recuperação máxima de massa (CONARD, 1992).

As perdas da etapa de manufatura geralmente são processadas na recuperação secundária do metal, por exemplo, por meio da aplicação de técnicas Gross Energy Requirement (GER), ou seja, de análises da energia bruta utilizada nessa recuperação, as quais determinarão se a recuperação almejada será, ou não, financeiramente atraente para o mercado.

$\mathrm{Na}$ etapa de processamento, no entanto, há relatos de várias melhoras, graças a otimizações e modelagens de situações e produtos (CONARD, 1992; DOYLE; DUYVESTEYN, 1993; YOSHIKI-GRAVELSINS et al., 1993). 


\subsection{Efluentes}

Como visto, as descargas no meio-ambiente podem ser sólidas, líquidas ou gasosas. O engenheiro ou o químico devem enfrentar o desafio de minimizá-las. A Tabela 6, a seguir, mostra alguns dos problemas mais evidentes em cada uma das etapas de produção já referidas, que carecem de soluções abrangentes, comparando-os, em termos relativos, quer se manifestem na terra, quer se manifestem na água ou no ar . Essa comparação remete aos padrões ambientais aceitos nos países da Organização para a Cooperação e o Desenvolvimento Econômico (OCDE), podendo - sempre é importante salientar - variar bastante entre países e grupos de metais.

Tabela 6: Comparação dos impactos dos efluentes em cada etapa de produção.

\begin{tabular}{l|c|c|c}
\hline \multicolumn{1}{c|}{ Produção } & Terra & Água & $\mathrm{Ar}$ \\
\hline Extração & $\mathrm{S}$ & $\mathrm{S}$ & $\mathrm{M}$ \\
Processamento & MS & MS & $\mathrm{S}$ \\
Fabricação & $\mathrm{B}$ & $\mathrm{B}$ & $\mathrm{S}$ \\
Manufatura & $\mathrm{B}$ & $\mathrm{B}$ & $\mathrm{B}$ \\
\hline
\end{tabular}

Os problemas específicos que enfrenta cada uma das indústrias que mineram e produzem metais são abordados na Internet, nos portais das associações e dos grupos de estudo - já há estudos, por exemplo, para o cobre, o chumbo, o zinco, o níquel, o alumínio e os metais leves outros que o alumínio -, e também na literatura (ver UNIDO, 1987; UNEP, 1993).

Dessa forma, o papel do engenheiro de minas, do metalúrgico, do químico, do hidrometalúrgico, do planejador ambiental e de outros especialistas no desenvolvimento de processos robustos, ambiental e socialmente, objetivo do desenvolvimento sustentável, estará focado particularmente nos seguintes efluentes:

a) na etapa de extração: movimentação e distúrbios geodinâmicos, naturais ou antropogênicos, em maciços rochosos, erosão, águas de minas, regimes hidrogeológicos, drenagem ácida, disposição de rejeitos, recuperação de áreas degradadas, etc.;

b) na etapa de processamento: efluentes ácidos, metais pesados, disposição de sólidos, geração de gases, etc.

Técnicas específicas e possíveis soluções para os problemas apresentados estão disponíveis na literatura. Para biossorção, extração líquido-líquido, eletrorrecuperação de soluções diluídas, membranas, o engenheiro de processo poderá consultar os textos citados na lista de referências (CONARD, 1992; DOYLE; DUYVESTEYN, 1993; NICOL, 1993), bem como suas versões mais recentes. 
A Tabela 7 lista alguns dos impactos ambientais associados a um grupo selecionado de ramos industriais metálicos, os quais utilizam a best available technology (BAT), ou seja, a melhor tecnologia disponível no mercado .

Tabela 7: Principais impactos ambientais para um grupo seleto de indústrias.

\begin{tabular}{cll}
\hline Metal & \multicolumn{1}{c}{ Impacto } \\
\hline $\mathrm{Al}$ & lama vermelha, HF, CO2, voláteis de piche, lineamentos dos potes \\
$\mathrm{Cu}$ & eletrolíticos, cianetos \\
$\mathrm{Zn}$ & $\mathrm{SO} 2$, fumos metálicos, metais pesados \\
$\mathrm{Ti}$ & $\mathrm{FeCl}$, cloretos voláteis, CO2 \\
$\mathrm{Ni}$ & Carbonila, metais pesados, poeiras e particulados \\
\hline
\end{tabular}

\section{OS MINERAIS COMO SOLUÇÕES AMBIENTAIS}

Até agora, a análise pôs em foco os efeitos no meio ambiente, causados pela extração, pelo processamento, pela fabricação e pela manufatura dos metais.

Vale a pena lembrar, inclusive para efeitos do ordenamento territorial mineiro - ver detalhes em Villas Bôas e Page (2002) -, que os minérios e minerais não podem ser vistos apenas como vilães, devem também ser considerados como soluções ambientais diretas.

Pressões sociais intensas e conseqüentes políticas agressivas espelhadas em legislações mais estritas forçam a disposição de rejeitos e o tratamento de águas, por exemplo, a ser mais eficaz e controlada; dessa forma, a utilização de bentonitas, cal, soda cáustica, hidróxido de magnésio, zeólitas, etc. é uma realidade de mercado (HARRIESREES, 1993), bem como abre amplas perspectivas de pesquisa e desenvolvimento para essas aplicações e usos.

\section{FECHAMENTO DE MINAS}

O fechamento de minas tem sido abordado nos últimos cinco anos de maneira bem diversa do que foi feito em estudos existentes em passado recente.

Desde a implantação da grande mineração, nos inícios do século $\mathrm{XX}$, as operações unitárias de lavra compreendem o acesso ao corpo mineralizado, a fratura do corpo mineralizado, o transporte do fraturado até a boca do britador primário e a recuperação da área degradada.

As três primeiras operações unitárias sempre foram realizadas, pois são inerentes à produção do bem mineral; já a quarta nem sempre, pois as legislações ambientais não existiam ou eram lenientes em relação 
a essa etapa, ficando totalmente a critério da empresa a decisão de realizá-la.

Pressões sociais, manifestas em pressões políticas originadas nos países centrais, fizeram com que essa quarta operação unitária não apenas se fizesse efetiva, mas, principalmente, assumisse um novo ângulo, ampliado, o do fechamento de mina.

Dessa forma, fechamento de mina é mais do que recuperação ambiental da área degradada, sendo a recuperação para usos futuros assegurada de forma sustentável, bem como tendo um componente de preocupação com a comunidade envolvida, antes inexistente. Do ponto de vista operacional, continua sendo uma operação unitária de engenharia de minas, com a preocupação, já na fase de projeto, de fazer o fechamento das frentes de lavra, à medida que avança a extração e concomitantemente com essa etapa.

Entretanto, se incorporar a preocupação com a comunidade existente, que vive de seu trabalho na mina, o projeto mineral deverá prever e prover recursos para a alocação e a diversificação de habilidades de mão-de-obra, à medida que se aproxima ou se sinaliza a exaustão da reserva. Para uma visão e uma análise mais completa sobre o tema, ver Villas Bôas e Barreto (2001).

\section{INDICADORES DE SUSTENTABILIDADE PARA A INDÚSTRIA EXTRATIVA MINERAL}

Uma das questões básicas tratada em recente reunião promovida pelo Projeto Mining, Minerals and Sustainable Development (MMSD), denominada global mining iniciative, levada à Conferência Mundial sobre o Desenvolvimento Sustentável (WSSD), a RIO +10, realizada em setembro de 2002 em Johannesburgo, na África do Sul, diz respeito à capacitação em temáticas relativas ao desenvolvimento sustentável e à atividade extrativa mineral.

Nesse contexto, é fundamental discutir e criar INDICADORES que acompanhem e balizem as decisões e conseqüentes ações.

Como quaisquer indicadores, os de sustentabilidade terão de ser relevantes, de fácil entendimento, confiáveis e baseados em dados existentes e acessíveis. Entretanto, diferem de outros indicadores, pois que não devem ser segmentados como os indicadores ambientais, sociais ou econômicos; devem, antes, ser holísticos a fim de abrangerem componentes sociais, econômicos, ambientais e políticos.

Considerem-se, por exemplo, o Produto Nacional Bruto (PNB) e o Índice de Bem-Estar Econômico Sustentável (IBES). Em si mesmo, o PNB, que mede a quantidade de dinheiro gerado em um país, é um índice econômico; o IBES subtrai do PNB as correções necessárias por causa 
da geração de conseqüências danosas ao PNB, bem como adiciona o valor de trabalho doméstico não remunerado.

Os indicadores de sustentabilidade para a indústria extrativa mineral foram objeto de recente debate em Carajás, Pará, e encontram-se disponíveis em livro eletrônico editado por Villas Bôas e Sánchez (2002).

\section{FUTURO DA INDÚSTRIA MINERAL NA AMAZÔNIA}

A questão do futuro da indústria mineral na Amazônia, pela sua própria amplitude, será apenas esboçada neste texto, pois que implica uma análise mais pormenorizada dos particulares eventos que existem ou serão criados na Amazônia.

É fundamental para essa questão discutir o ordenamento territorial amazônico e sua vertente industrial. Nessa vertente, é necessário comparar a atividade extrativa mineral e outras concorrentes, como a agropecuária, a silvicultura, a indústria em geral, bem como delimitar e definir áreas de manejo florestal, áreas protegidas, discutir as questões relativas à exploração em terras indígenas, etc.

Tais questões têm sido objeto de discussões que deverão servir de base para a tomada de decisões relativas ao futuro da indústria mineral na Amazônia. Ver, por exemplo, Simonian (2000), Coelho (2000) e Antonius (2000). 


\section{REFERÊNCIAS}

ANTONIUS, P. A. J. Legislação mineradora no Brasil e sua importância para o meio ambiente. In: COELHO, M. C. N.; SIMONIAN, L. T. L.; FENZL, N. (Org.). Estado e políticas públicas na Amazônia: gestão de recursos naturais. 1 ed. Belém: CEJUP, 2000, v. 1. p. 171

BAHR, A.; PRIESEMANN, Th. The Concentration of Gold Ores. In: WORKSHOP RARE AND PRECIOUS METALS, Castelo Ivano,Universitá di Trento, Italy, 1988.

BEEVER, M. B. The Recycling of Metals: I. Ferrous Metals; II. NonFerrous Metals. Conservation \& Recycling, 1976, v. 1.

BEEVER, M. B. Materials, Technology Change and Productivity. Materials \& Society, v. 6, n. 4, 1982.

CHAPMAN, P. F.; ROBERTS, F. Metal Resources and Energy. Boston, MA: Butterworth, 1983.

COELHO, M. C. N. Política e gestão ambiental (des)integrada dos recursos minerais na Amazônia Oriental. In: COELHO, M. C. N.; SIMONIAN, L. T. L.; FENZL, N. (Org.). Estado e políticas públicas na Amazônia: gestão de recursos naturais. 1 ed. Belém: CEJUP, 2000, v. 1. p. $117-170$.

CONARD, B. R. The Role of Hydrometallurgy in Achieving Sustainable Development. Hydrometallurgy, Amsterdam, n. 30, p. 1-28, 1992.

CORRY, A. V.; KIESSLING, O. E. Mineral Technology and Output per Man Studies: Grade of Ore. Philadelphia: Works Progress Administration, 1938. $114 \mathrm{p}$.

DOYLE, F. M.; DUYVESTEYN, S. Aqueous Processing of Minerals, Metals, and Materials. 1993 Review of Extraction Processing. JOM, p. 46-54, April, 1993.

FORREST, D.; SZEKELY, J. Global Warming and the Primary Metals Industry. JOM, p. 23-30, December 1991.

HARRIES-REES, K. Minerals in Waste and Effluents Treatment. Industrial Minerals, n. 308, p. 29-39, May 1993.

HASIALIS, M. D. Improvements in Minerals Recovery. National Materials Policy. National Academy of Science, Proceedings, Washington, D.C., 1975.

MALENBAUM, W. World Demand for Raw Materials in 1985 and 2000. University of Philadelphia Publication Series, 1978. 
MAR, J. W. Testimony at Hearings of the Subcommittee on Science, Technology and Space of the Committee on Commerce, Science and Transportation of the Senate. Washington, D.C., U.S.G.P.O., 1981.

NICOL, M. J. Progress in Electrometallurgy Research and Applications. 1983 Review of Extractive \& Processing. JOM, p. 55-58, April 1993.

SIMONIAN, L. T. L. Políticas públicas, desenvolvimento sustentável e recursos naturais em áreas de reserva na Amazônia brasileira. In: COELHO, M. C. N.; SIMONIAN, L. T. L.; FENZL, N. (Org.). Estado e políticas públicas na Amazônia: gestão de recursos naturais. 1 ed. Belém: CEJUP, v. 1. 2000.

TILTON, J. E. Atrophy in Metal Demand. Materials and Society, v. 10, n. 3. 1986.

UNITED NATIONS ENVIRONMENTAL PROGRAM. Environmental Management of Nickel Production: A Technical Guide. Paris, 1993 (Technical Report, 15).

UNITED NATIONS INDUSTRIAL DEVELOPMENT ORGANIZATION. Pollution Problems and Solutions in the Non-Ferrous Metals Industry. First Consultation on the Non-Ferrous Metals Industry, ID/WG, 470/3, Budapest, Hungary, 1987.

VILLAS BÔAS, R. C. Aluminium: Why Search for New Production Rules? In: ENCONTRO NACIONAL DE TRATAMENTO DE MINÉRIOS, 4., 1976. Anais. São José dos Campos, 1976.

VILLAS BÔAS, R. C. Strategic Ores: Worldwide and Brazilian Prospectives. In: ENCONTRO DO HEMISFÉRIO SUL SOBRE TECNOLOGIA MINERAL, 2., 1987. Anais. Rio de Janeiro, 1987.

VILLAS BÔAS, R. C.; BARRETO, M. L. Cierre de Minas. CYTED/IMAAC, 2001. Disponível em: <http://www.cetem.gov.br/cyted-xiii > ; <ttp:// www.cetem.gov.br/imaac >. Acesso em 22 de janeiro de 2003.

VILLAS BÔAS, R. C.; PAGE, R. La Minería en el Contexto de la Ordenación del Territorio. Mendoza: CYTED/CNPq, 2002.

WADDELL, L. M.; LABYS, W. C. Transmaterialization: Technology and Materials Demand Cycles. Materials and Society, v. 12, n. 1, 1988.

YOSHIKI-GRAVELSINS, K. S. et al. Metals Production, Energy and the Environment. Past I: Energy Consumption. JOM, p. 15-20, May 1993. 